\title{
Application of the Harmonic Search Algorithm for Identification of Model Parameters of Traffic Lights for a High Way of Bogotá
}

\author{
Oswaldo Alberto Romero Villalobos ${ }^{1}$, Edgar Jacinto Rincón Rojas ${ }^{2}$ \\ Julio Barón Velandia ${ }^{3}$, Helbert Eduardo Espitia Cuchango ${ }^{4}$ \\ ${ }^{1,2,3,4}$ Facultad de Ingeniería, Universidad Distrital Francisco José de Caldas, Bogotá, Colombia.
}

ORCIDs: 0000-0001-8308-3128 (Oswaldo), 0000-0002-2997-8075 (Edgar), 0000-0002-9491-5564(Julio), 0000-0002-0742-6069 (Helbert)

\begin{abstract}
This document presents the process for identifying the parameters of a stochastic model for a traffic light intersection of the Circunvalar avenue of Bogotá. Traffic light simulation is performed as a Poisson process. Model parameters are estimated from actual measurements using the harmonic search optimization algorithm. The results show that the proposed identification process allows an adequate identification of model parameters.
\end{abstract}

Keywords: Identification, parameters, transport, traffic light, simulation.

\section{INTRODUCTION}

The transportation need in large cities and the regulation of urban traffic systems are subjects of study of great importance [1]. Urban growth makes transport systems more complex by increasing delays as well as environmental problems [2].

To achieve safety and agility in the traffic of intersections, the development of adequate traffic light systems is necessary. In this way, traffic regulators allow mobility management at intersections with a large flow of vehicles [3], [4].

On different approaches to the simulation of traffic lights intersections, in [5] a proposal is presented to model urban traffic through a continuous-time model. An analysis is also performed using methods based on hybrid Petri nets. The reported results show that the two approaches used have similar results.

On the other hand, in [6] a model of discrete events is presented to model the control of a traffic light for a simple intersection. The intersection model is made as a queuing $\mathrm{M} / \mathrm{M} / 1$ type considering a FIFO type structure, for the vehicle's arrival time an exponential type probability distribution is used. Other related work can be observed in [7] where the design of a fuzzy controller is developed for a traffic light intersection controller, where priority is considered for emergency vehicles.

Reference [8] states that the efficiency in the flow control of a traffic light intersection depends on the control of the phases and the time of these, additionally, [8] proposed an adaptive model to control the sequence of the traffic light phases and the duration using modified sequencing algorithms.
Finally, [9] presents an overview and simulation of a vehicular traffic model, which describes the dynamics of a single-vehicle that travels through a sequence of traffic lights that turn on and off with a specific frequency. The model considers the accelerated and decelerated of the vehicle. The main result of this work shows the effects of the traffic light cycle on the dynamic behavior of the system.

On the other hand, the harmonic algorithm corresponds to the group of algorithms of evolutionary optimization where a population is used to perform the optimization process. This algorithm is based on those used to adjust a piece of music. The stochastic characteristics of the algorithm allow the optimization of a process that also has a stochastic behavior such as a traffic light intersection. Considering the parameters of the model as the variables to optimize, it is possible to use this algorithm for the adjustment of parameters of the intersection model.

The first part of the document describes the modeling and simulation of a traffic light intersection located on the Circunvalar avenue of Bogotá city. The traffic light simulation is carried out as a Poisson process, where the arrival rates of the cars, as well as the passing of these cars are modeled through exponential type distributions. Parameter identification is then performed using the Harmonic Search optimization algorithm, for which real measurements of the intersection are used. The final part of the document shows the results obtained from the identification process by comparing them with real measured data. It is hoped that this work can serve as a reference so that in future developments different alternatives for a traffic light plan can be evaluated.

\section{FRAMEWORK}

This section describes the concepts used for the model and simulation of the traffic light intersection, as well as the harmonic search algorithm, which is used for the identification of parameters. First, there is a review of the concepts related to the stochastic model for the process of arrival and departures of vehicles at a traffic light. Secondly, the type of distribution used to model the arrival and departure of vehicles is described. Subsequently, the harmonic search optimization algorithm is presented. 


\section{II.I Poisson Process}

A Poisson process can be defined as a process of counting the number of events that occur in the interval $[0, t]$. To define a Poisson process it can take a small time interval $\Delta t$, present during the times $t$ and $t+\Delta t$, as can be seen in Fig 1 .

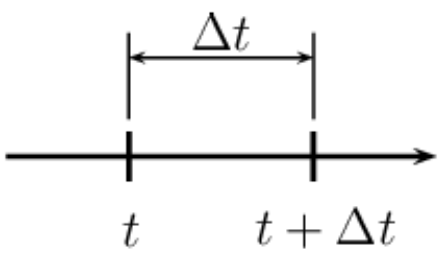

Fig. 1. Time interval [10].

In a Poisson process, the number of events that occur in disjoint intervals of time are independent, also corresponding to a pure birth process because in an infinitesimal time $\Delta t$ interval only one arrival can occur with an independent probability $\lambda \Delta t$ of arrivals outside the interval, where $\lambda$ corresponds to the arrival rate of the vehicles.

Considering Fig 2 and taking a finite interval $T$, the probability $p(k)$ of $k$ arrivals at $T$ is given as:

$$
p(k)=\frac{(\lambda T)^{k} e^{-\lambda T}}{k !} \quad k=0,1, \ldots
$$

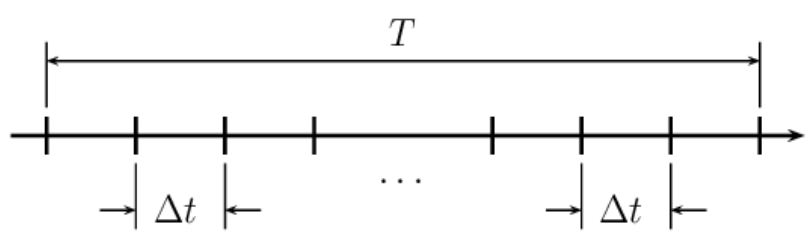

Figura 2: Time intervals [10].

According to [10] the simulation of a Poisson process can be done with the following steps:

1. Initialization with $t=0, N=0$.

2. Generate a uniformly distributed randomnumber $r \in U(0,1)$.

3. Calculate $t=t+[-(1 / \lambda) \ln (r)]$.

4. Stop the process if $t>T$, otherwise continue.

5. Update $N=N+1$ and $t_{N}=t$.

6. Return to step 2 .

\section{II.II Exponential Distribution}

In the model used for the traffic light intersection, both the arrival $\lambda_{i}$ and departure rates $\mu_{i}$ are considered parameters of an exponential distribution for the respective route $i=1,2, \ldots, N$.
The exponential distribution has a cumulative probability function:

$$
F(t)=1-e^{-\lambda t}
$$

In this case, to generate an exponentially distributed random variable $T$ with parameter $\lambda$, is used:

$$
U=1-e^{-\lambda T}
$$

Where $U$ is a random number distributed (uniform) in the interval $[0,1]$. In this, it is possible calculate:

$$
T=-\frac{1}{\lambda} \ln (1-U)
$$

\section{II.III Harmonic Search Algorithm}

A stochastic optimization algorith is used while considering such stochastic characteristic of the trafic model. The harmonic search algorithm is used for the optimization process since it has a rapid convergence rate [11], also requiring few parameters in its configuration [12].

According to [13], [14] the Harmonic Search algorithm (HS) aims to mimic the process of musical improvisation, where the adjustment of a sequence of sounds and silences is performed.

From the musical perspective, the algorithm consists in the adjustment of harmony, which corresponds to the concordance between the sounds that are presented simultaneously, and also to the sequence with neighboring sounds. In this way, for the implementation of the algorithm, harmony corresponds to the set of solution vectors and a matrix or harmony memory is used, which resembles the experience process in adjusting harmony. For the implementation of the algorithm, the matrix or memory of harmony has the following form:

$$
H M=\left[\begin{array}{lllll}
x_{1,1} & x_{1,2} & \cdots & x_{1, N} & f\left(x_{1}\right) \\
x_{2,1} & x_{2,2} & \cdots & x_{2, N} & f\left(x_{2}\right) \\
\vdots & \vdots & \ddots & \vdots & \vdots \\
x_{K, 1} & x_{K, 2} & \cdots & x_{K, N} & f\left(x_{K}\right)
\end{array}\right]
$$

Where $x_{j, i}$ with $i=1,2, \ldots, N$ corresponds to the number of decision variables and $j=1,2, \ldots, K$ are the number of possible solutions stored in the memory matrix. On the other hand, $f\left(x_{j}\right)$ is the objective function evaluated for the respective solution $x_{j}$. The steps involved in the optimization process are:

1. Initialization of the algorithm parameters.

2. Initialization of harmony memory.

3. Selection of a harmony (solution vector).

4. Pitch adjustment.

5. Harmony memory update.

6. If the completion criterion is not met, return to step 2.

7. Establish the final solution. 
In the first stage of the algorithm, the values $x_{j, i}$ of the Harmony Memory (HM) are determined randomly. In the second instance, a value $x_{r, i}$ of the harmony memory is randomly selected using a probability value $0 \leq H M C R \leq 1$ (Harmony Memory Considering Rate). With the values selected for each dimension $i$ a new harmony vector is constructed (Vector Harmony) $x_{r}=\left[\begin{array}{llll}x_{r, 1} & x_{r, 2} & \ldots & x_{r, N}\end{array}\right]$. As a third step the vector $x_{r}$ is taken and a tone adjustment is made by testing with neighboring notes. For this it is used $U(-1,1) \in[-1,1]$ a uniformly distributed random number and $F W$ (Fret Width, Formerly Bandwidth) the frequency band to adjust the tone, thus considering a probability $0 \leq$ $P A R \leq 1$ (Pitch Adjusting Rate) the pitch adjustment is:

$$
x_{r, i}= \begin{cases}x_{r, i}+F W \cdot U(-1,1) & \text { if; } P A R \\ x_{r, i} & \text { if; } 1-P A R\end{cases}
$$

As a fourth instance, it is possible to see if the new harmony vector $x_{r}$ has a better performance than the worst vector of the harmony matrix $x_{W}$ is replaced by $x_{r}$. As a final stage, it is repeated from the second step until a criterion of completion is met.

\section{TRAFFIC LIGHT INTERSECTION MODEL}

Among the different forms that exist for the modeling of traffic lights intersections there are models where accelerations and vehicle speeds are considered. These variables in many cases are taken as deterministic; however, being given by human behavior these variables acquire a random character.

Given the above, a stochastic model is considered to address the modeling problem for vehicular traffic situations and traffic lights. The proposed model considers the car flows randomly as well as the time it takes for them to cross the intersection.

The intersection considered is described in [15] where there are three possibilities for vehicles to pass through the traffic light, which are mainly given by the two configurations shown in Fig 3.

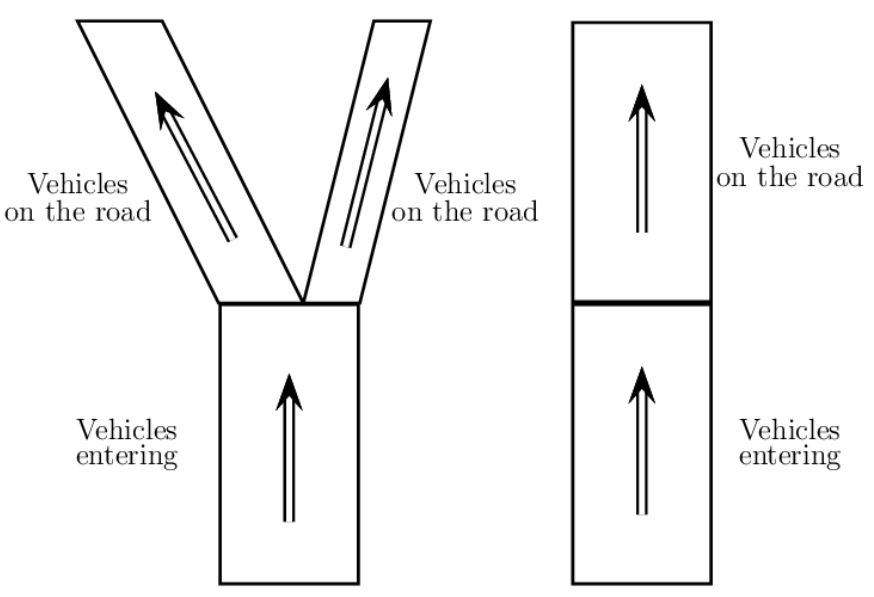

Fig 3. Possible intersection behaviors.
In general terms, the input of vehicles is governed by a PDF (Probability Distribution Function) associated with each road. The exit of vehicles is given by PDFs that represent the time it takes for vehicles to pass through the intersection.

\section{III.I Model Variables}

As mentioned earlier, the system is influenced by the following random variables:

- Arrival time of vehicles at the intersection: the parameter associated with this variable is $\lambda_{i}$ that corresponds to the arrival rate of the vehicles for the respective route $i=1,2,3$.

- Time taken for the car to make the crossing when the traffic light is green. In this case, the associated parameter is $\mu_{i}$ that corresponds to the exit rate of vehicles on the road.

\section{III.II Data Adquisition and Adaptation}

To estimate the model parameters associated with the arrival time between vehicles and the time they take to cross the intersection, the data acquisition system described in [15] is implemented, however, this system is limited to carrying out the counting of the vehicles that cross the intersection every 5 minutes. This is an important aspect when carrying out the simulation of the model for the implementation of the optimization process.

\section{III.III Model Simulation}

To perform the simulation of the model, according to [16] and [17], the main steps described below are implemented:

1. Initialization with $t=0, N=0$.

2. Cycle for $N$ :

3. Generate a uniformly distributed random number $r \in U(0,1)$.

4. If $r<\lambda \Delta t$ a car arrives and is located in the queue.

5. If the traffic light is green:

6. Generate a uniformly distributed random number $q \in U(0,1)$.

7. If $q<\mu \Delta t$ the vehicle that is in line passes through the traffic light.

8. Return to step 2 increasing $t=1+\Delta t, N=N+1$.

\section{EXPERIMENTAL DATA}

The experimental data were taken thanks to the temporary authorization by the Secretaría Distrital de Movilidad (District Department of Mobility) at the intersection of Circunvalar avenue and Jiménez avenue, which includes the intersections with Calle de la Quinta de San Pedro Alejandrino (Jiménez avenue) and Funicular avenue in front of the entrance of 
ascent to the hill of Monserrate, this intersection can be seen in Fig 4.

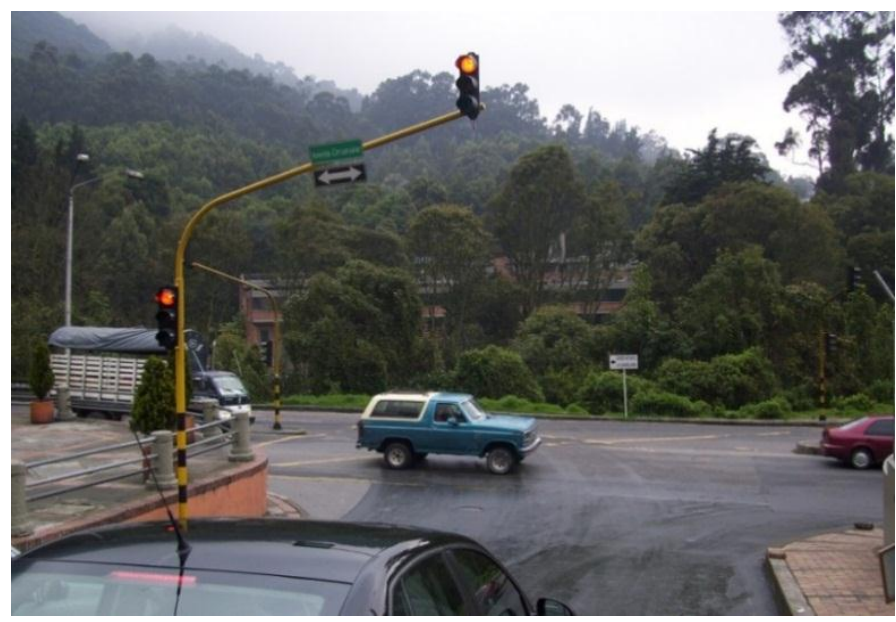

Fig 4. Intersection environment.

Additionally, in Fig 5 is observed the geometric configuration of the area of the traffic measurement system.

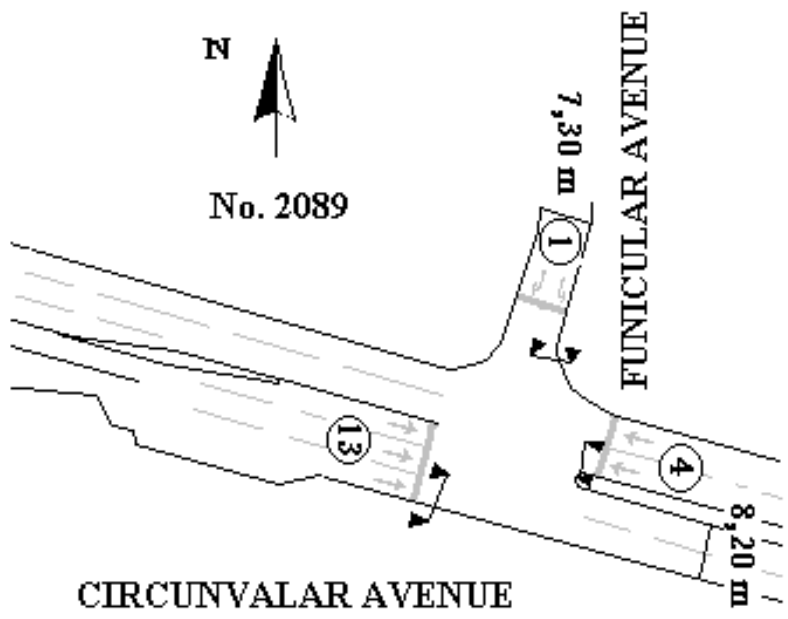

Fig 5. Scheme of the geometric configuration of the intersection.

The intersection is geometrically formed by the following vehicle groups, based on the nomenclature of the Secretaría Distrital de Movilidad (see Fig 5).

Vehicular group identified with 13, which corresponds to the vehicles that come from east to west along the ring road.

The vehicle group identified with 4 corresponds to the vehicles that come from the west to the east along the ring road.

Vehicular group identified with 1 , which includes vehicles that from Funicular avenue (one way only) take Circunvalar avenue to the east or west. For data collection, several sensors were located on the road (one per lane and centered) in vehicle groups 13,4 and 1 . The location of these is given 1.5 to 2.5 meters before the line of sight of the bracket which holds the traffic light. The system flexibly reports the sensor data, taking a cumulative interval of 5 minutes for the visualization of results (for traffic analysis).

In accordance with the configuration established for this intersection, data are taken with the planning previously prepared by the engineers of the Secretaría Distrital de Movilidad, taking as an example the measurements shown in Fig 6, 7, and 8 in which only the data taken is presented for a Monday day, the other results can be consulted in [18].

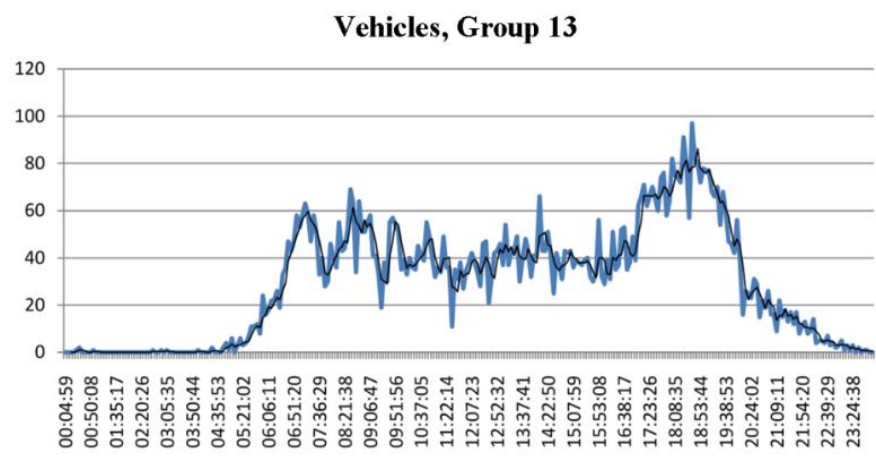

Fig 6. Number of vehicles in group 13 on Monday taking 5 minutes sampling time.

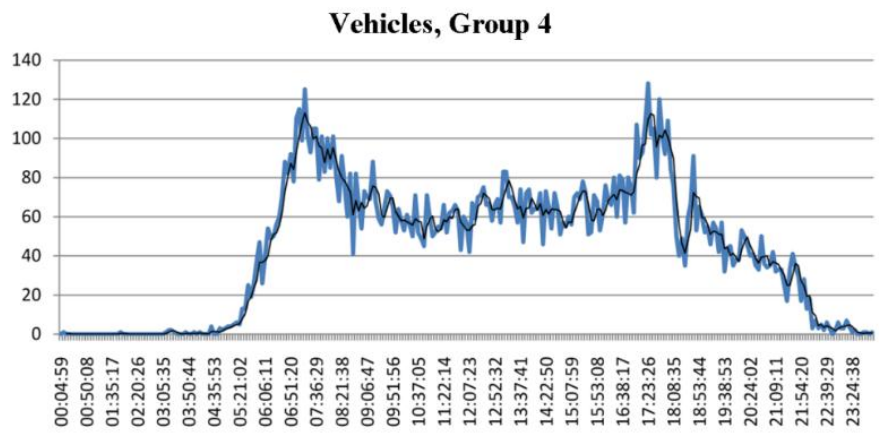

Fig 7. Number of vehicles in group 4 on Monday taking 5 minutes sampling time.

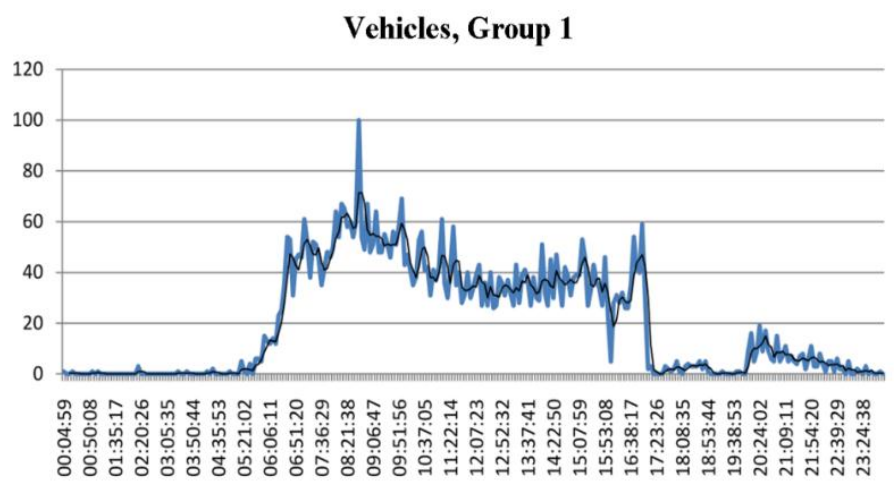

Fig 8. Number of vehicles in group 1 on Monday taking 5 minutes sampling time. 
Table 1. Traffic lights time.

\begin{tabular}{|c|c|c|c|c|c|c|c|c|c|c|c|c|c|c|c|c|c|c|}
\hline & Phases & 1 & 2 & 3 & 4 & 5 & 6 & 7 & 8 & 9 & 10 & 11 & 12 & 13 & 14 & 15 & 16 & 17 \\
\hline & Seconds & 17 & 3 & 1 & 2 & 14 & 2 & 1 & 1 & 1 & 1 & 39 & 1 & 2 & 1 & 1 & 2 & 1 \\
\hline \multirow{3}{*}{ 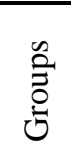 } & 1 & 4 & 2 & 1 & 1 & 1 & 1 & 1 & 1 & 1 & 1 & 1 & 1 & 1 & 3 & 3 & 4 & 4 \\
\hline & 4 & 1 & 1 & 1 & 3 & 4 & 4 & 4 & 4 & 4 & 4 & 4 & 2 & 2 & 1 & 1 & 1 & 1 \\
\hline & 13 & 1 & 1 & 1 & 3 & 4 & 4 & 4 & 4 & 4 & 4 & 4 & 4 & 2 & 2 & 1 & 1 & 1 \\
\hline
\end{tabular}

The model is considered for the valley (stable) schedule which presents the greatest amount of data. In this way, the data is taken from 10:00 am to 4:30 pm. At this time, the traffic light times are presented in Table 1 . These data correspond to the itinerary from Monday to Thursday in the corresponding plan from 9:30 am to $5 \mathrm{pm}$. This table presents a cycle with duration of 90 seconds where: 1-Red, 2-Yellow, 3-RedYellow, 4-Green.

\section{OPTIMIZATION PROCESS}

To perform the optimization process it is used a function that implements the system simulation, allowing the possibility of adjusting the model parameters. With this function the respective value of the objective function is calculated, which is optimized by the harmonic search algorithm. In this way, the optimization process consists of the following elements:

1. Application of the optimization algorithm.

2. Calculation of the objective function.

3. System simulation (traffic light).

Considering the stochastic characteristics of the model and the optimization algorithm, 20 executions of this algorithm are made for each configuration. To establish the algorithm configurations, what is presented in [19], [20], and [21] is taken as a reference, where:

- HMS : Harmony memory size, usually with values from 1 to 100 (typical value 30).

- HMCR: Probability for the selection of a harmony memory value, values between 0.7 and 0.99 (typical value 0.9 ).

- PAR: Probability to adjust the tone, with values between 0.1 and 0.5 (typical value 0.3 ).

- $F W$ : Maximum setting value, can be between $\left(0.01 \cdot L_{U}\right)$ and $\left(0.001 \cdot L_{U}\right)$, where $L_{U}$ it corresponds to the length of the search space.

In this way, Table 2 presents the configurations for the Harmonic Search algorithm.

Table 2. Harmonic Search algorithm configurations.

\begin{tabular}{|l|c|c|c|c|}
\hline Configuration & $H M S$ & $H M C R$ & $P A R$ & $F W$ \\
\hline Configuration 1 & 5 & 0.9 & 0.5 & 0.1 \\
\hline Configuration 2 & 10 & 0.95 & 0.5 & 0.1 \\
\hline Configuration 3 & 15 & 0.95 & 0.35 & 0.1 \\
\hline
\end{tabular}

The respective results of each configuration are presented in Table 3 where the maximum, minimum, average value and standard deviation (STD) are shown.

Table 3. Results of the optimization process.

\begin{tabular}{|c|c|c|c|}
\hline \multicolumn{4}{|c|}{ Group 13} \\
\hline Value & $\begin{array}{c}\text { Configuration } \\
1\end{array}$ & $\begin{array}{c}\text { Configuration } \\
2\end{array}$ & $\begin{array}{c}\text { Configuration } \\
3\end{array}$ \\
\hline Max & 41.795 & 39.41 & 42.282 \\
\hline Min & 30.359 & 33.333 & 31.500 \\
\hline Average & 36.229 & 36.606 & 36.720 \\
\hline STD & 2.6863 & 1.4533 & 2.6329 \\
\hline \multicolumn{4}{|c|}{ Group 4} \\
\hline Value & $\begin{array}{c}\text { Configuration } \\
1\end{array}$ & $\begin{array}{c}\text { Configuration } \\
2\end{array}$ & $\begin{array}{c}\text { Configuration } \\
3\end{array}$ \\
\hline Max & 78.462 & 50.538 & 53.615 \\
\hline Min & 41.667 & 40.949 & 39.795 \\
\hline Average & 47.769 & 46.882 & 47.723 \\
\hline STD & 7.7576 & 2.9649 & 3.3593 \\
\hline \multicolumn{4}{|c|}{ Group 1} \\
\hline Value & $\begin{array}{c}\text { Configuration } \\
1\end{array}$ & $\begin{array}{c}\text { Configuration } \\
2\end{array}$ & $\begin{array}{c}\text { Configuration } \\
3\end{array}$ \\
\hline Max & 29.026 & 31.244 & 29.423 \\
\hline Min & 21.679 & 23.218 & 22.308 \\
\hline Average & 26.435 & 26.927 & 26.871 \\
\hline STD & 1.8371 & 2.1466 & 1.799 \\
\hline
\end{tabular}

Taking the optimized parameters of the best case, Fig 9 displays the respective simulation for group 13 where $\lambda=0.0535$ and $\mu=0.2313$; Fig 10 for group 4 with $\lambda=0.0828$ and $\mu=0.1267$. Finally the group 1 in Fig 11 having $\lambda=0.0462$ and $\mu=0.3683$. 


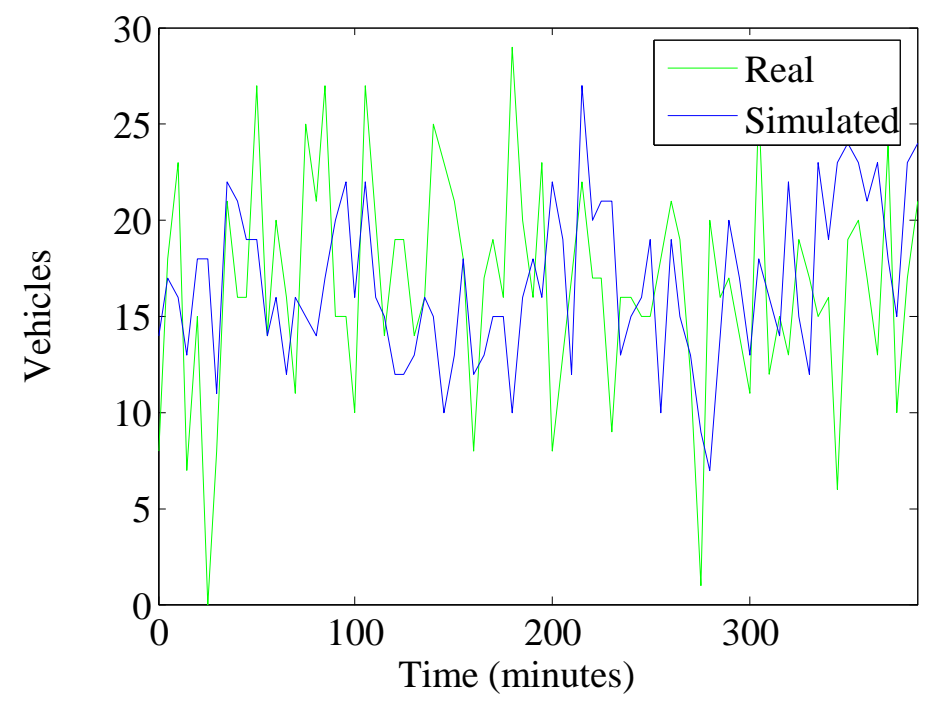

Fig 9. Simulation result for the best case of group 13.

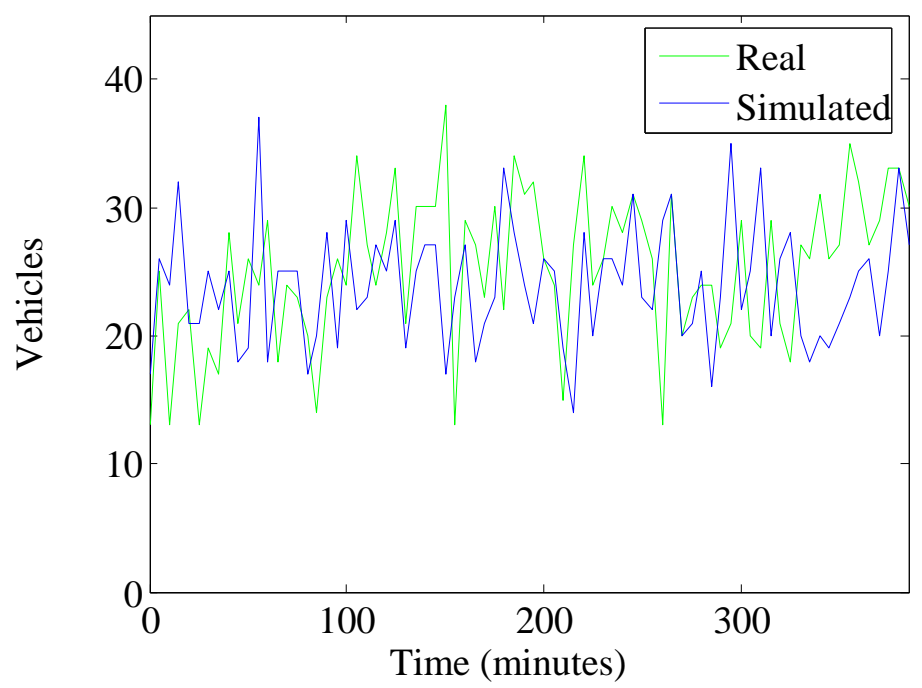

Fig 10. Simulation result for the best case of group 4.

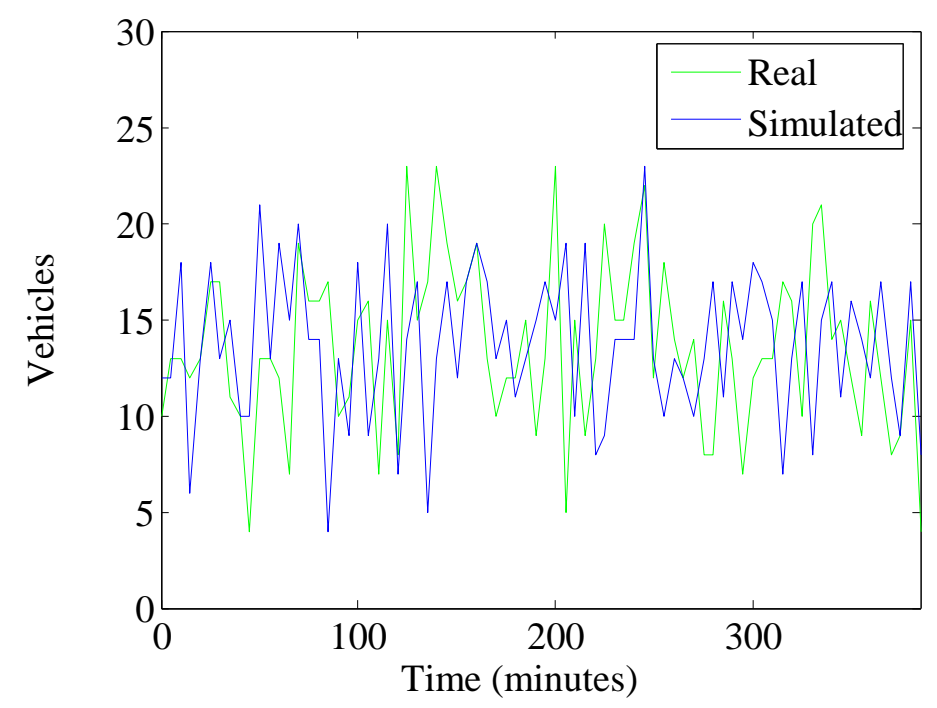

Fig 11. Simulation result for the best case of group 1.

\section{DISCUSSION}

This work develops a trafic model for a schedule where a homogeneous behavior is presented (valley time); however, to have a complete model, a schedule with different behaviors would be used. For this, clustering techniques can be used in order to establish groups of data that would be associated with peak and valley schedules. This article limits the analysis to achieve the identification of parameters for a particular schedule, leaving the possibility of expanding the model in subsequent works using clustering techniques.

\section{CONCLUSIONS}

Stochastic modeling is a suitable alternative when the systems under study are very complex to be described by deterministic equations, especially when interaction between human beings is involved.

Considering the stochastic behavior of the implemented model, the stochastic characteristics of the harmonic search algorithm allow handling the identification of parameters of the traffic light intersection model.

With the results obtained it was possible to verify that it is feasible to identify the stochastic model considered using the harmonic search algorithm.

It is expected to extend the model for different schedules, for which grouping techniques can be used to establish these schedules.

In the future, it is expected to collect new data to have an updated model of the intersection.

\section{Acknowledgements}

The authors express their gratitude to the Facultad de Ingeniería de la Universidad Distrital Francisco José de Caldas as well as to the Secretaría Distrital de Movilidad de Bogotá.

\section{REFERENCES}

[1] D. Robles, P. Ñañez, N. Quijano, Control y simulación de tráfico urbano en Colombia: Estado del arte, Revista Ingeniería Universidad de los Andes, 29, 2009, 59-69.

[2] I. Thomson, A. Bull, La congestión del tránsito urbano: causas y consecuencias económicas y sociales, Revista Cepal, 76, 2002,109-121.

[3] O. Salcedo, J. Pedraza, C. Hernández, Modelo de Semaforización Inteligente para la Ciudad de Bogotá, Revista Ingeniería, 11(2), 2007, 61-69.

[4] L. Pedraza, C. Hernández, D. López, Control de tráfico vehicular usando ANFIS, Ingeniare, Revista chilena de ingeniería, 20(1), 2012, 79-88.

[5] M. Voinescu, A. Udrea, S. Caramihai, On Urban Traffic Modelling and Control. CEAI, 11(1), 2009, 1018. 
[6] S. Sumaryo, A. Halim, Improved Discrete Event Simulation Model of Traffic Light Control on A Single Intersection, IEEE Quality in Research, 2013.

[7] M. Jha, S. Shukla, Design Of Fuzzy Logic Traffic Controller For Isolated Intersections With Emergency Vehicle Priority System Using MATLAB Simulation, CSIR Sponsored X Control Instrumentation System Conference, 2013.

[8] A. Aljaafreh, N. Al-Oudat, Optimized Timing Parameters for Real-Time Adaptive Traffic Signal Controller, UKSim-AMSS 16th International Conference on Computer Modelling and Simulation, 2014.

[9] M. Mesa, J. Valencia, G. Olivar, Model for a vehicle dynamics through a sequence of traffic lights, DYNA, 81(184), 2014, 138-145.

[10] K. Giesecke, H. Kakav, M. Mousavi, Exact Simulation of Point Processes with Stochastic Intensities, Operations Research, 59(5), 2011, 1233-1245.

[11] K.S. Lee, Z.W. Geem, A new metaheuristic algorithm for continuous engineering optimization, harmony search theory and practice, Computer Methods in Applied Mechanics Engineering, 194(36-38), 2005, 3902-3933.

[12] M. Mahdavi, M. Fesanghary, E. Damangir, An improved harmony search algorithm for solving optimization problems, Applied Mathematics Computation, 188(2), 2007, 1567-1579.

[13] O. Alia, R. Mandava, The variants of the harmony search algorithm: an overview, Artificial Intelligence Review, 36(1), 2011, 49-68.

[14] M. Segura, Estimación automática de acordes para uso en transcripción musical a partir de audio. Trabajo Fin de Grado en Ingeniería en Sonido e Imagen en Telecomunicación, Universidad de Alicante, España, 2015.

[15] O. Romero, J. Barón, H. Espitia, Prototipo de un controlador de tráfico para una intersección semaforizada, Visión electrónica, 9(1), 2015, 58-66.

[16] B. Hahn, D. Valentine, Essential MATLAB for Scientists and Engineers, Academic Press, Third edition, 2007.

[17] N. Nafi, M.K. Hasan, A. Abdallah, Traffic Flow Model for Vehicular Network, International Conference on Computer and Communication Engineering (ICCCE), 2012.

[18] O. Romero, Diseño de un modelo de controlador flexible para un sistema integrado de transporte que permita superar las deficiencias actuales en captura de datos e intercambio entre sistemas heterogéneos. Tesis de maestría en ingeniería industrial, Universidad Distrital Francisco José de Caldas Facultad de Ingeniería, 2013.
[19] R. Diao, Q. Shen, Deterministic parameter control in harmony search, UKWorkshop on Computational Intelligence (UKCI), 2010, 1-7.

[20] A. Khadwilard, P. Luangpaiboon, P. Pongcharoen, Full factorial experimental design for parameters selection of Harmony Search Algorithm, The Journal of Industrial Technology, 8(2), 2012, 1-10.

[21] Z. Geem, K. Sim, Parameter-setting-free harmony search algorithm, Applied Mathematics and Computation, 217(8), 2010, 3881-3889. 